\title{
An analysis of indications of caesarean sections at Tezpur medical college and hospital, Tezpur (a government hospital)
}

\section{Purashree Sarma, Rumen Chandra Boro*, Partha Sarathi Acharjee}

Department of Obstetrics and Gynaecology, Tezpur Medical College and Hospital, Bihaguri, Sonitpur District, Assam, India

Received: 26 March 2016

Revised: 08 April 2016

Accepted: 11 April 2016

*Correspondence:

Dr. Rumen Chandra Boro,

E-mail: drcboro@gmail.com

Copyright: (C) the author(s), publisher and licensee Medip Academy. This is an open-access article distributed under the terms of the Creative Commons Attribution Non-Commercial License, which permits unrestricted non-commercial use, distribution, and reproduction in any medium, provided the original work is properly cited.

\section{ABSTRACT}

Background: The main objective of this study is to analyze the indications of caesarean section so as to find out what measures should be taken to bring down the rate without hampering maternal and foetal outcome.

Methods: It is an observational study which was carried out at the obstetrics \& gynaecological department of TMCH from 01.01.2015 to 31.12.2015. All antenatal cases attending both OPD and the emergency services during the above period who finally delivered via caesarean section were taken up for this study. There were no exclusion criteria. Data were collected from hospital records for the study.

Results: There were a total of 8255 deliveries during the study period out of which, 2278 had delivered via Caesarean Section. So, the rate of caesarean section in the study was found to be $27.60 \%$.

Conclusions: Caesarean Section is one of the most widely performed surgical procedures in obstetrics worldwide. It is undoubtedly a lifesaving surgical method both for the mother and the child. In present study also a high rate of Caesarean deliveries was observed in a tertiary care centre in rural Assam namely Tezpur Medical College and Hospital. The rate can be brought down by reducing the incidence of primary caesarean section and also by practising VBAC (Vaginal Birth after Caesarean).

Keywords: Caesarean section, Indication, Teaching hospital

\section{INTRODUCTION}

Caesarean section is the removal of a child through an incision in the abdominal wall and the uterine wall of the mother. The term should neither be applied to the removal of a child from the abdomen after rupture of the uterus, nor to an operation for abdominal pregnancy. ${ }^{1}$ Undoubtedly, it is the most widely performed obstetrical surgery worldwide.

Though WHO recommends a rate of $10-15 \%$ caesarean section for a given hospital, there has been a rising trend worldwide. ${ }^{2}$ The indications vary from institution to institution and also between government setup and private hospitals. ${ }^{3}$ Both elective (C/S done as a planned surgery) and emergency (unplanned $\mathrm{C} / \mathrm{S}$ done for proper maternal or foetal indication) cases carry different risks so far as maternal and perinatal morbidity and mortality are concerned. ${ }^{4}$ The rate depends on the type of care giver and the facility available in a given set up. ${ }^{5}$ In India, the $\mathrm{C} / \mathrm{S}$ rate was $8.5 \%$ in 2010 , but a phenomenal increase of $40 \%$ was seen in Kerala and Tamil Nadu. ${ }^{5}$ The factors responsible for this trend include-increased institutional deliveries, inadequate foetal surveillance system, lack of trained man power, fear of the patient for labour pain, busy schedule of the obstetrician specially those working in private sector and also an apprehension on the Obstetrician regarding the fear of poor neonatal outcome. ${ }^{6}$ Apart from foetal distress repeat caesarean section was an important indication. 
A collaborative study in ICMR (Indian Council of Medical Research) in 1980 observed $13.8 \%$ rate of C/S in teaching hospitals. To study the escalating rate of $\mathrm{C} / \mathrm{S}$ another study was conducted among 30 medical colleges all over India and results analysed which showed a rate of $\mathrm{C} / \mathrm{S}$ at $21.8 \%$ in $1993-94$ and $25.4 \%$ in $1998-99{ }^{7}$

As seen in 2001 census, the percentage of women who had undergone $\mathrm{C} / \mathrm{S}$ was found to be highest in Kerala (31.8\%) followed by Andhra Pradesh (29.3\%) and Tamil Nadu $(23.2 \%)$ and the lowest rate was observed in Rajasthan and Jharkhand (4.2\% in both the states). ${ }^{8}$

The Oldest Obstetrics \& Gynaecological department of India, The Eden Hospital of Calcutta Medical College, Kolkata has seen a rise in $\mathrm{C} / \mathrm{S}$ from $9.5 \%$ in 1973 to $40.1 \%$ in $2012 .^{8}$

\section{METHODS}

It is an observational study conducted at the Obstetrics \& Gynaecology Department of Tezpur Medical College and Hospital, Assam for the period-01.01.2015 to 31.12.2015. All antenatal cases attending the OPD as well as emergency services, i.e. labour room, who finally delivered their babies via $\mathrm{C} / \mathrm{S}$ were taken up for the present study. Both elective and emergency cases were included and there were no exclusion criteria. Data for the study was obtained from the patient's ticket and Hospital records. Data were analyzed and interpreted as required.

\section{RESULTS}

There were a total of 8255 deliveries during the period of 01.01.2015 to 31.12.15 out of which, 2278 had delivered via $\mathrm{C} / \mathrm{S}$. So, the rate of $\mathrm{C} / \mathrm{S}$ in the study was found to be $27.60 \%$.

Table 1: Indication of LSCS.

\begin{tabular}{|lll|}
\hline Indication & Patient count & Percentage \\
\hline Foetal distress & 706 & 30.99 \\
\hline Repeat C/S & 524 & 23.00 \\
\hline Induction failure & 319 & 14.00 \\
\hline PIH & 296 & 12.99 \\
\hline Oligohydramnios & 114 & 5.00 \\
\hline CPD & 46 & 2.02 \\
\hline Malpresentation & 69 & 3.03 \\
\hline Obstructed labour & 67 & 2.94 \\
\hline APH & 46 & 2.02 \\
\hline Prolonged labour & 68 & 2.99 \\
\hline BOH & 23 & 1.01 \\
\hline Total & 2278 & 100 \\
\hline
\end{tabular}

Out of 2278 deliveries, $92.41 \%$ were from rural areas and it was significantly higher in the age group of 21 to 30 years (76.29\%). More C/S cases were seen being performed on primigravidas $(70.02 \%)$ cases compared to multigravidas (29.98\%). Also, around $72 \%$ cases were unbooked, i.e. cases with no antenatal checkups. Regarding the indications, it was observed that the foetal distress was the commonest one followed by repeat caesarean section and failed induction. Most of the cases were done as an emergency basis $(83.98 \%)$ compared to elective C/S cases. ${ }^{9}$ Majority of the cases (97.98\%) belonged to lower socio economic strata with very low literacy rate.

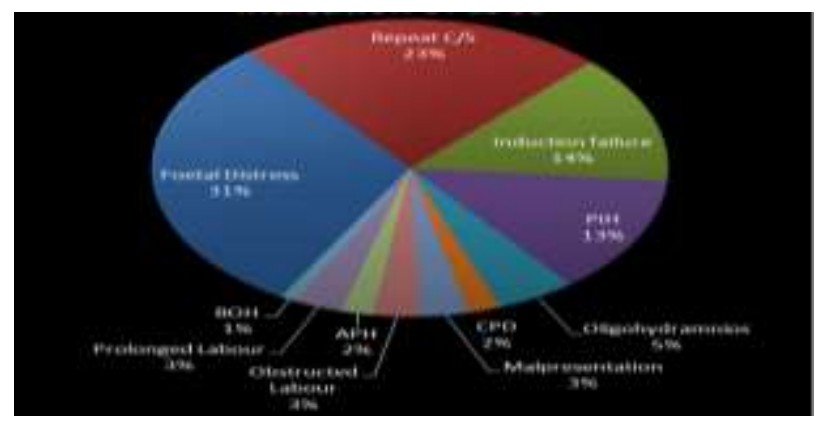

Figure 1: Pie diagram showing indications of LSCS.

Table 2: Age wise distribution of $\mathrm{C} / \mathrm{S}$ deliveries.

\begin{tabular}{|lll|}
\hline Age group & Patient count & Percentage \\
\hline$<20$ years & 321 & 14.09 \\
\hline $21-30$ years & 1738 & 76.29 \\
\hline$>30$ years & 219 & 9.62 \\
\hline Total & 2278 & 100 \\
\hline
\end{tabular}

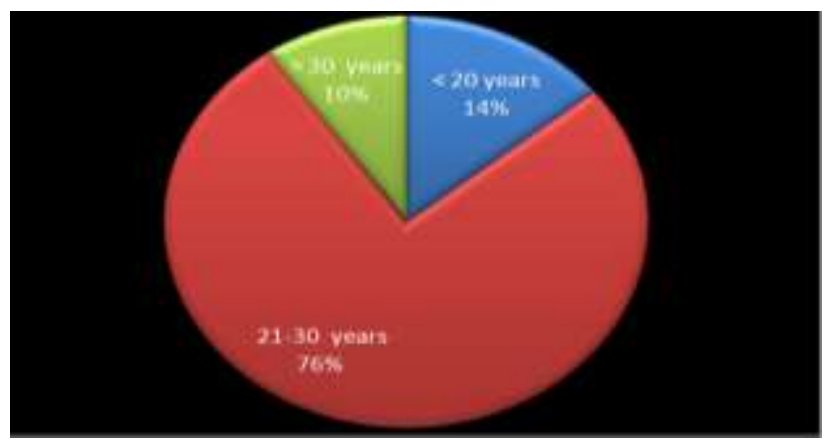

Figure 2: Pie diagram showing age wise distribution of CS deliveries.

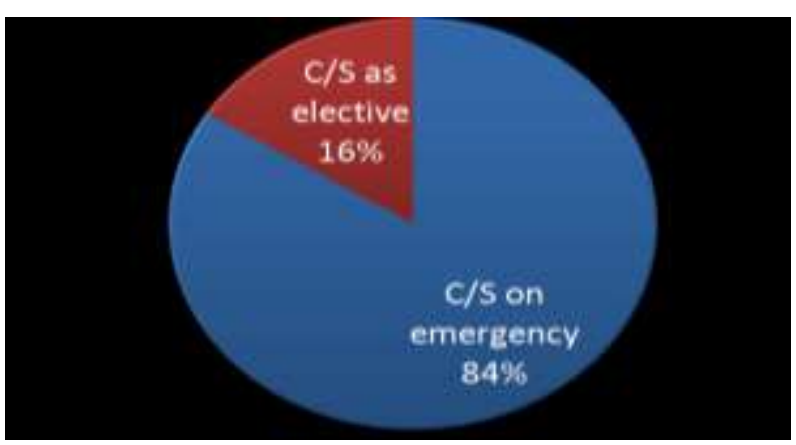

Figure 3: Pie diagram showing emergency vs elective caesarean sections. 
Table 3: Emergency vs elective caesarean sections.

\begin{tabular}{|lll|}
\hline C/S Alternatives & Patient Count & Percentage \\
\hline Emergency & 1913 & 83.98 \\
\hline Elective & 365 & 16.02 \\
\hline Total & 2278 & 100 \\
\hline
\end{tabular}

Table 4: Area wise distribution of $\mathrm{C} / \mathrm{S}$ deliveries.

\begin{tabular}{|lll|}
\hline Area & Patient count & Percentage \\
\hline Rural & 2105 & 92.41 \\
\hline Urban & 173 & 7.59 \\
\hline Total & 2278 & 100 \\
\hline
\end{tabular}

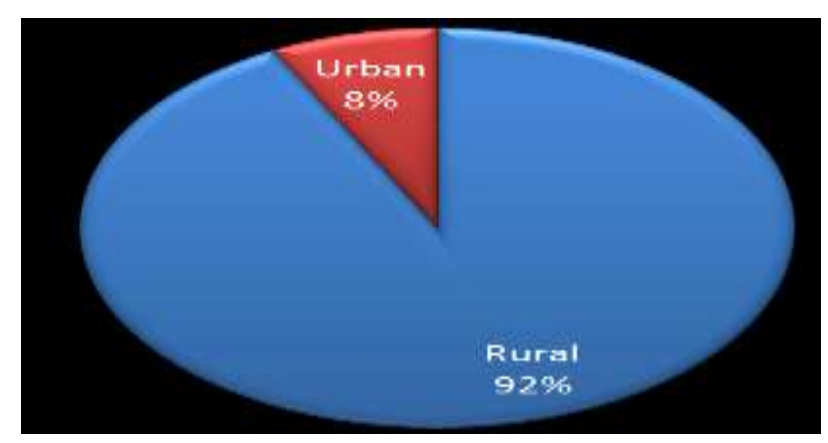

Figure 4: Pie diagram showing area wise distribution of CS deliveries.

Table 5: Patient Distribution based on socio economic background.

\begin{tabular}{|lll|}
\hline Area & Patient count & Percentage \\
\hline Low & 1890 & 82.97 \\
\hline Middle & 342 & 15.01 \\
\hline High & 46 & 2.02 \\
\hline Total & 2278 & 100 \\
\hline
\end{tabular}

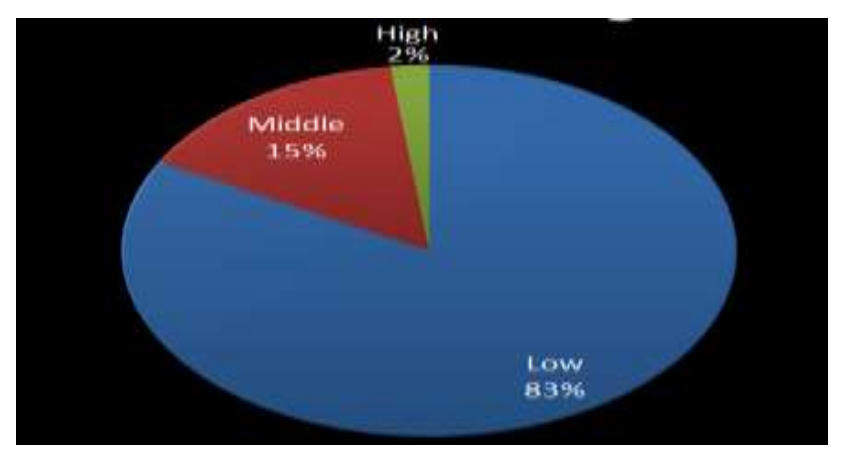

Figure 5: Pie diagram showing patient distribution based on socio-economic background.

Table 6: Parity wise distribution of $\mathrm{C} / \mathrm{S}$ cases.

\begin{tabular}{|lll|}
\hline Parity & Patient count & Percentage \\
\hline Primigravidas & 1595 & 70.02 \\
\hline Multigravidas & 683 & 29.98 \\
\hline Total & 2278 & 100 \\
\hline
\end{tabular}

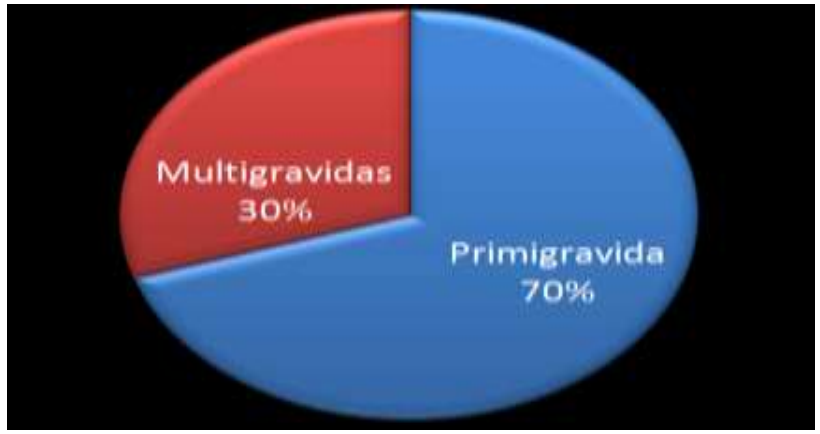

Figure 6: Pie diagram showing parity wise distribution of CS cases.

\section{DISCUSSION}

The present study was conducted in a rural tertiary care unit, i.e. Tezpur Medical College \& Hospital which is the only such hospital on the North Bank of River Brahmaputra in Assam. As such, the most of the cases attending the OPD and also those availing the emergency services are basically referred cases from the nearby and also some of the distant PHC (Primary Health Centre), CHC (Community Health Centre), Sub divisional Dispensaries and the Civil Hospitals. Given the situation, most of the cases had to be delivered via Caesarean Section owing to delayed referral, delayed arrival and poor logistics. The condition is further worsened by preexisting anaemia, untreated hypertension, irregular antenatal checkups and gross ignorance and negligence of pregnancy and its outcome.

In the present study the rate of $\mathrm{C} / \mathrm{S}$ observed is $27.60 \%$ which is similar to the outcome of $24.4 \%$ in the study carried out by Kambo I et.al and 31.15\% observed by K. Padmaleela et al. ${ }^{10,11}$ Significantly both the studies were carried out at teaching hospitals. In another study conducted by Bhasin et al, a higher caesarean section rate of $34.4 \%$ was observed in East Delhi. ${ }^{12}$

The observations of the present study are comparable to the study carried out by Yallapa Jadhav et al at Latur Govt. Medical College where Caesarean section rate was found to be $23.97 \%{ }^{13}$

The rising trend of Caesarean delivery has also been observed in the United States since 1996 when the rate was $21 \%$. In 2007, the rate was the highest ever recorded at $32 \%$, representing 1.4 million births and a $53 \%$ increase since $1996 .^{1{ }^{4}}$

In our study, common indications for Caesarean Section were foetal distress $(30.99 \%)$, repeat C/S (23\%), failed induction (14\%), PIH (12.99\%), oligohydramnios (5\%), CPD (2.02\%), malpresentation (3.03\%), obstructed labour (2.94\%), APH (2.02\%), prolonged labour (2.99\%) and $\mathrm{BOH}(1.01 \%)$. These observations are in similar to the findings carried out in the study conducted at Latur, Madhya Pradesh by Prashant Bade et al where the 
following rates were observed. ${ }^{13}$ Foetal distress $(11.7 \%)$, repeat $\mathrm{C} / \mathrm{S} \quad(24.8 \%)$, failed induction (14\%), oligohydramnios (2\%), CPD (17.6\%), malpresentation (6.8\%), obstructed labour (3.1\%), APH (2.1\%) and prolonged labour (16.6\%).

In another study conducted at Rural Medical College in the state of Haryana from Jan 2007 to Dec 2012, G. Singh et al observed the following rates regarding indications of caesarean section. ${ }^{3}$ Foetal distress $(12.1 \%)$, repeat $\mathrm{C} / \mathrm{S} \quad(29.7 \%)$, $\mathrm{PIH} \quad(4.8 \%), \quad \mathrm{CPD} \quad(5.1 \%)$, malpresentation $(11.3 \%), \mathrm{APH}(5.9 \%)$ and prolonged Labour (25.4\%).

\section{CONCLUSIONS}

Vaginal birth is and will always be regarded as the superior mode of delivery compared to $\mathrm{C} / \mathrm{S}$, simply because it has lesser morbidity and mortality involving both the mother and the child. As such, the obstetricians all over the world must encourage vaginal delivery as far as possible. Caesarean section due to maternal/foetal indication is inevitable in emergency situations as a lifesaving procedure. Elective Caesarean sections done on mother's request may be minimised by proper counselling during antenatal period. ${ }^{15}$ So focus should be placed on trial of more cases for VBAC (Vaginal Birth after Caesarean) and most importantly reducing primary Caesarean Section rate. ${ }^{16}$ Timely done and properly performed by skilled persons, Caesarean section carries a low morbidity and mortality rate. This can be attributed to improved surgical technique and modern anaesthetic procedures. The JSY (Janani Suraksha Yojna) introduced by Govt. of India has been successful in making Caesarean deliveries more acceptable and affordable to the women belonging to the lower socio-economic class. $^{17}$

\section{Funding: No funding sources}

Conflict of interest: None declared

Ethical approval: The study was approved by the Institutional Ethics Committee

\section{REFERENCES}

1. Mudaliar AL, Menon MKK. Gopalan S, Jain V. Mudaliar and Menon's Clinical Obstetrics. $12^{\text {th }}$ edition. Orient BlackSwan Pvt. Ltd; 2015:398.

2. WHO, HRP. WHO statement on caesarean section rates, Executive summary, Ref. WHO/RHR/15.02.

3. Singh G, Gupta ED. Rising incidence of caesarean section in rural area in Haryana, India: a retrospective analysis. Internet $\mathrm{J}$ Gynecol Obstetr. 2013;17(2):1-5.

4. Hannah ME. Planned elective cesarean section: A reasonable choice for some women? CMAJ. 2004;170(5):813-4.

5. Shrivastava D, Chaudhry P. Rising trend of caesarean section in rural India: a prospective study. GJMR. 2015;15(4):17-20.

6. Manjulatha B, Sravanthi TP. Caesarean section rates in a Teaching Hospital: a ten year review. IOSR J Dent Med Sci. 2015;14(8):1-5.

7. Arjun G. Caesarean section: evaluation, guidelines and recommendations. Indian $\mathrm{J}$ Med Ethics. 2008;5(3):117-20.

8. Shabnam S. Caesarean section delivery in India: causes and concerns, international union for the scientific study of population, session 221, assessments of facility-based delivery services.

9. Daniel S, Viswanathan M, Simi BN, Nazeema A. Study of maternal outcome of emergency and elective caesarean section in a semi-rural tertiary Hospital. Natl J Med Res. 2014;4(1):14-8.

10. Kambo I, Bedi N, Dhillon BS, Saxena NC. A critical appraisal of caesarean section rates at teaching hospitals in India. Int $\mathbf{J}$ Gynaecol Obstet 2002;79(2):151-8.

11. Padmaleela K, Thomas V, Prasad KV. An analysis of the institutional deliveries and their outcomes in government teaching hospitals of Andhra Pradesh, India. IJHSR. 2013;3(5):76-81.

12. Bhasin SK, Rajoura OP, Sharma AK, Metha M, Gupta N, Kumar S et al. A high prevalence of caesarean section rate in East Delhi. Indian J Comm Med. 2007;32(3):222-4.

13. Bade P, Kendre V, Jadhav Y, Wadagale A. An analysis of indications for caesarean section at government medical college, Latur. Intern J Recent Trends Sci Technol. 2014;11(1):6-8.

14. Menacker F, Hamilton BE. Recent trends in cesarean delivery in the United States. NCHS Data Brief. 2010;35:1-8.

15. Committee opinion. The American College of Obstetricians and Gynecologists. 2013;559:1-4.

16. Black M, Entwistle VA, Bhattacharya S, Gillies K. Vaginal birth after caesarean section: why is uptake so low? Insights from a meta-ethnographic synthesis of women's accounts of their birth choices. BMJ Open. 2016;6(1):1-13.

17. Janani Suraksha Yojana (MoH and FW, Government of India) Guidelines launched from April 2005.

Cite this article as: Sarma P, Boro RC, Acharjee PS. An analysis of indications of caesarean sections at Tezpur medical college and hospital, Tezpur (a government hospital). Int J Reprod Contracept Obstet Gynecol 2016;5:1364-7. 